\title{
Xanthogranulomatous pyelonephritis in childhood
}

\author{
F M J Quinn, A C Dick, M T Corbally, M B McDermott, E J Guiney
}

\begin{abstract}
Background-Xanthogranulomatous pyelonephritis is a severe, atypical form of chronic renal parenchymal infection accounting for $6 / 1000$ surgically proved cases of chronic pyelonephritis. Its manifestations mimic those of neoplastic and other inflammatory renal parenchymal diseases and, consequently, it is often misdiagnosed preoperatively.

Aim-To examine the relation between clinical history and the results of renal investigations performed in children with xanthogranulomatous pyelonephritis.

Method-A retrospective review of 31 cases presenting with the histopathological diagnosis of xanthogranulomatous pyelonephritis between 1963 and 1999.

Results-The mean follow up was 8.2 years. The male:female ratio was $1: 1.1$. The left kidney was affected in 26 of the 31 patients. The positive findings on examination and investigation at presentation were: fever, 16 children; pyuria, 26 children; positive urine culture, 16 children. A haemoglobin of $<100 \mathrm{~g} / 1$ was measured in 27 of 31 patients and 15 of 18 patients tested had a raised erythrocyte sedimentation rate of $>20 \mathrm{~mm}$ in the first hour. Twenty six children had renal calculi, with a large reduction in the function of the affected kidney on isotope scintigraphy in 27 of the 29 patients tested. Hypertrophy of the contralateral kidney, shown on imaging, was present in 17 of 31 patients. Conclusions-Increasing awareness of this condition should lead to the diagnosis being suspected preoperatively.

(Arch Dis Child 1999;81:483-486)
\end{abstract}

Keywords: nephrectomy; xanthogranulomatous pyelonephritis

Department of Surgery, Our Lady's Hospital for Sick Children, Crumlin, Dublin 12, Republic of Ireland

F M J Quinn

A C Dick

M T Corbally

E J Guiney

Department of Pathology, Our Lady's

Hospital for Sick

Children

M B McDermott

Correspondence to: Dr Quinn.

Accepted 25 June 1999 no large series of xanthogranulomatous pyelonephritis in children has been reported. all cases, with no long term sequelae. To date,
We report a retrospective review of 31 patients presenting to this unit between 1963 and 1999, the largest series of children with this disease to be reported to date.

\section{Patients and methods}

The hospital records of all 31 patients presenting to our unit with xanthogranulomatous pyelonephritis between 1963 and 1999 were examined. There were 16 girls and 15 boys aged between 7 months and 14 years at presentation. Details of symptoms at presentation, investigations, operative findings, and histological findings of the affected kidney were recorded. The mean follow up was 8.2 years (range, 2 months to 20 years).

\section{Results}

There was a history of previous urinary tract infection in only eight patients and the symptoms were of relatively short duration (less than three weeks in all cases). Diagnosis was made preoperatively in 20 of the last 21 patients presenting with xanthogranulomatous pyelonephritis. Before that, the preoperative clinical diagnoses were very varied: Wilms's tumour (2), splenomegaly as a result of leukaemia (2), intestinal obstruction (1), perinephric abscess (2), hepatomegaly (1), osteomyelitis (1), and failure to thrive (1).

Sixteen of the 31 children had fever at the time of presentation. Only four patients had a haemoglobin $>100 \mathrm{~g} / 1$ and 11 had a haemoglobin of $<80 \mathrm{~g} / 1$. The erythrocyte sedimentation rate (ESR) was raised to $>30 \mathrm{~mm}$ in the first hour in 15 of 18 patients in whom this test was performed (range, $20-145 \mathrm{~mm}$ in the first hour). Nineteen children had a polymorph leucocytosis. In 15 patients the urine was sterile but appreciable pyuria was present in 10 of these. Of the 16 children with bacteriuria, Proteus strains grew in eight, Escherichia coli strains in five, and there was a mixed growth of bacteria in the remaining three patients.

Radiological investigation revealed multiple renal calculi in 26 patients and in one patient there was a ureteric stone associated with multiple renal calculi. In 17 patients intravenous urography and an ultrasound scan of the kidneys revealed hypertrophy of the contralateral non-affected kidney. In 29 patients DTPA (diethylenetriamine pentaacetic acid) renography was performed. In 23 of these, there was no function in the affected kidney and poor function $(<10 \%$ relative function) was found in four of the remaining six patients. The left kidney was affected in 26 of the 31 children.

At surgery, the affected kidney was enlarged in 21 patients and densely adherent to the surrounding tissues in all patients. In three instances, the kidney was adherent to the 


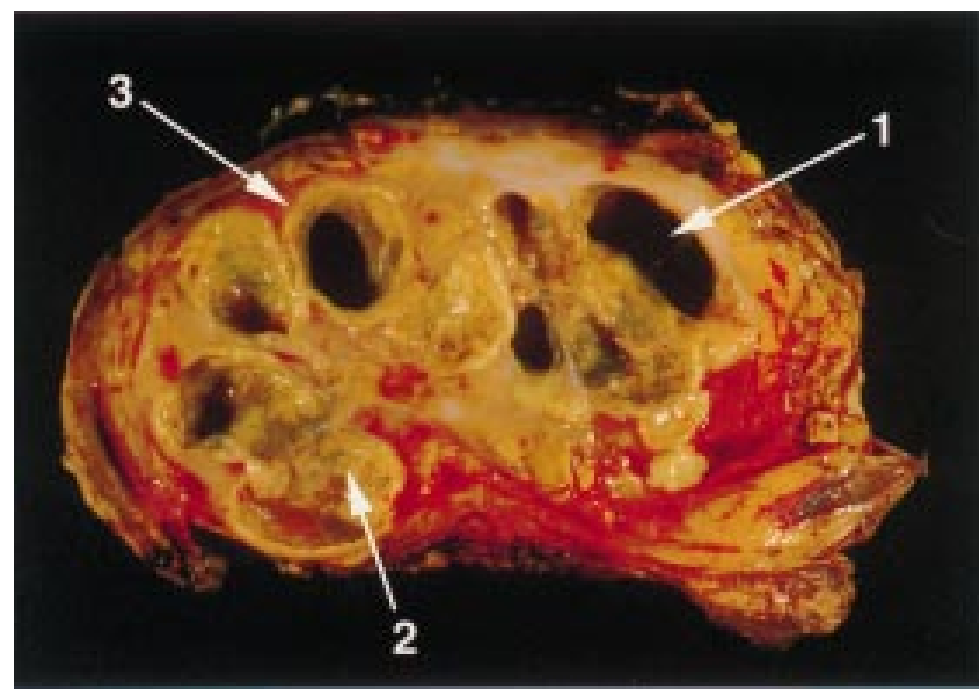

Figure 1 Macroscopic features of xanthogranulomatous pyelonephritis: dilated calyx (1); dilated calyx filled with pus (2); yellow tinge of fat laden macrophage layer (3).

descending colon, necessitating a partial colonic resection with the kidney in one patient; in another patient, the small intestine was adherent to an abscess at the lower pole of the affected kidney, causing intestinal obstruction. Perinephric abscess cavities were present in four children. Total nephrectomy was performed in 29 children. In one girl, the disease process was confined to the upper pole of a duplex kidney, and an upper pole nephrectomy was achieved. In another, an area of focal disease was identified as an abnormality on an

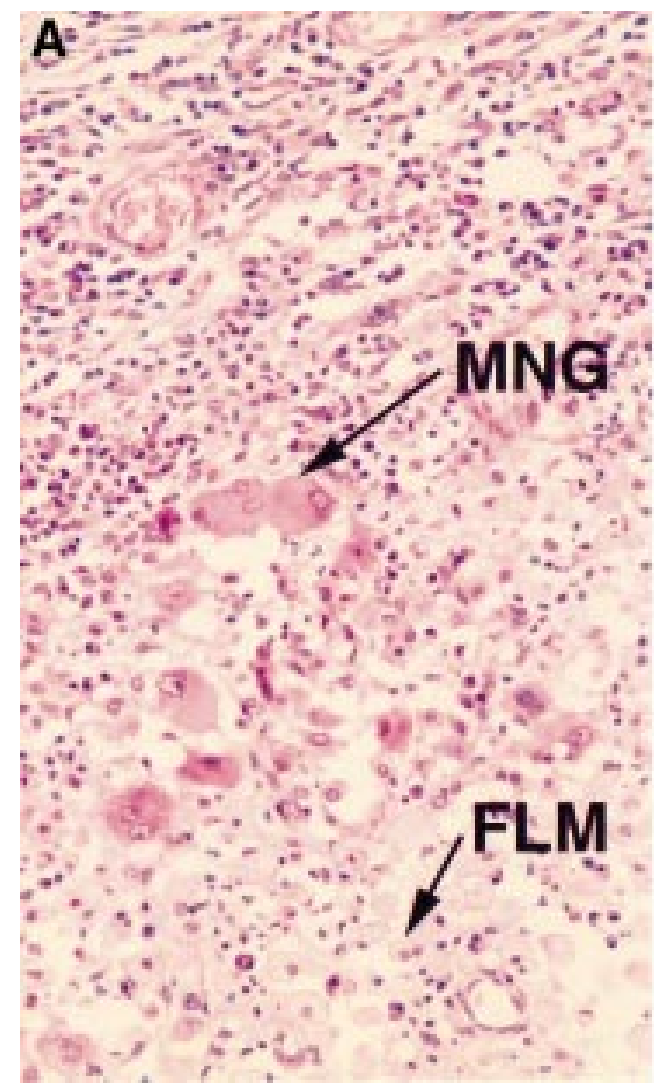

ultrasound scan and confirmed by biopsy. A limited resection was performed to remove the focal area of inflammation. In three patients was there clear evidence of pelviureteric junction obstruction.

In all instances, the cut surface of the kidney showed diffuse cortical scarring with considerable effacement of the normal renal architecture. Areas with the distinctly yellow tinge, which give the condition its name, were seen grossly in most patients, either as scattered foci or as a discrete rim around dilated, pus filled calyces or other cystic spaces (fig 1).

Microscopically, the kidneys showed a mixed acute and chronic inflammatory cell infiltrate with giant cells and lipid laden macrophages (fig 2). Such foci were usually surrounded by dense fibrous tissue and both inflammation and fibrosis clearly extended beyond the renal capsule in most of the cases examined. Contiguous, less severely affected areas of the kidney frequently showed more conventional histological features of chronic pyelonephritis.

In the intervening time after nephrectomy, one child had a lower pole nephrectomy on the contralateral side as a result of reflux nephropathy and urolithiasis in the lower pole of a duplex kidney. Three years after nephrectomy, at the age of 7 years, a further child developed renal failure. Renal biopsy at this stage showed evidence of amyloid in the remaining kidney. On reviewing previous histology, amyloid had not been present at the time of the nephrectomy.

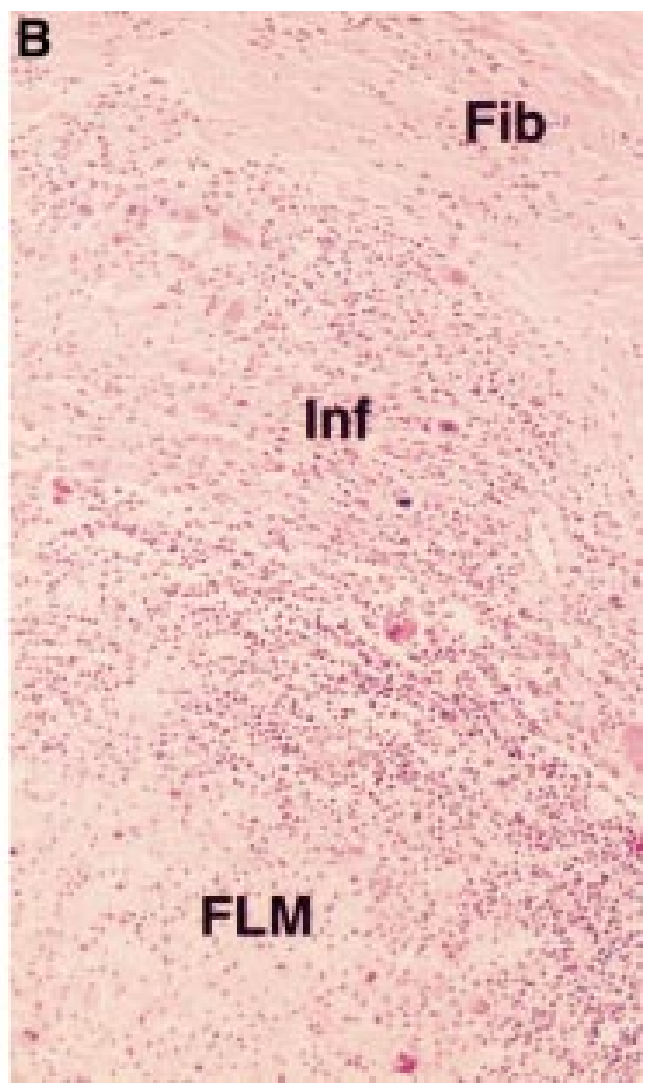

Figure 2 (A) Histological features of xanthogranulomatous pyelonephritis ( $\times 20$ magnification) showing multinucleated giant cells (MNG) and fat laden macrophages (FLM). (B) Histological features of xanthogranulomatous pyelonephritis $(\times 4$ magnification) showing fibrosis (Fib), inflammatory infiltrate (Inf), and fat laden macrophages (FLM). 


\section{Discussion}

Several interrelated aetiological features are thought to be responsible for the pathogenesis of xanthogranulomatous pyelonephritis. They include calculus or non-calculus urinary obstruction, ineffectively treated urosepsis, chronic renal ischaemia causing localised alterations in renal metabolism, lymphatic obstruction, alterations in lipid metabolism, and finally an altered immune response. The extent of the pathological process within the affected kidney varies. In the rare localised form, the lesion can be confined to one or other pole, as was seen in one part of a duplex kidney in our series. More commonly, a diffuse process is seen involving the whole kidney, leading in most cases to a decrease in renal function. The inflammatory process with extension into the perirenal tissues and adjacent organs causes great variety in the clinical presentations of xanthogranulomatous pyelonephritis.

Many reports on this disease conclude that preoperative diagnosis is not easy and this viewpoint seems to have been generally accepted, given the protean manifestations of the disease. However, we think that because of the increasing awareness of the condition, this is a diagnosis that can and should be made preoperatively. Indeed, in 20 of our last 21 cases the diagnosis was made before surgery. The characteristics of the condition that might help in a preoperative diagnosis of xanthogranulomatous pyelonephritis include: disease is usually unilateral (although very rare bilateral cases have been reported); renal function is absent or grossly impaired on the involved side; large, often numerous, renal calculi are present; anaemia, raised ESR, and leucocytosis are often present.

These characteristics might not all be present-for example, no stones were found in five of our 31 patients, but combinations of most of these findings suggest a diagnosis of xanthogranulomatous pyelonephritis. However, confirmation of this diagnosis depends on histological examination of the resected kidney.

Treatment of this disease is surgical excision of the diseased tissue. In most cases this will mean a total nephrectomy. However, in the relatively rare cases where the localised form of the disease is found, which involves only a single pole of the kidney, it might be possible to carry out a partial nephrectomy (as was the case in one of our patients). When performing surgery, it is very useful if the correct preoperative diagnosis has been made because surgery in this condition can be extremely difficult as a result of the inflammatory process extending beyond the boundaries of the kidney. In many cases, the kidney will have to be dissected off the major vessels. Therefore, it is unusual for the kidney to be able to be removed without opening the peritoneum, and an extensive anterolateral transperitoneal approach, such as that used in resection of a Wilms's tumour, is recommended rather than the standard lumbar renal incisions for nephrectomy.

It is generally accepted that once the diseased kidney has been removed the future prognosis for the affected child is excellent.
When a patient loses a kidney, the opposite kidney's compensatory response is remarkable. In infancy and childhood, the remaining solitary kidney undergoes hypertrophy and can even double in size to the extent that the mass of the solitary kidney will nearly equal the original combined mass of both kidneys. ${ }^{15-17} \mathrm{At}$ the time of surgery, 17 of the 31 patients had hypertrophy of the contralateral kidney, suggesting chronic poor function of the diseased kidney. At follow up, 12 of the 16 patients examined had an easily palpable contralateral solitary kidney. This was confirmed on ultrasound scan in many cases. Although reports on both adults and children suggest that there is no predilection for any particular side, ${ }^{18}{ }^{19}$ our study suggests that there is a large bias towards the left side. In the adult form of the disease, there is no predilection for any particular side and there is no clinical, anatomical, or pathological reason for this bias towards the left side. In the only other large series of this condition in children there is no bias towards any one side. ${ }^{19}$ Our results challenge previous claims that the focal variety of the disease is more common in children, ${ }^{8122021}$ because only one of 31 patients in our series had focal disease. Even in the patient in whom xanthogranulomatous pyelonephritis was confined to one pole of a duplex system, histology confirmed a diffuse inflammatory process throughout the whole pole. This is in agreement with many recent series. ${ }^{92}$

One child in our series appeared to have normal renal function based on the single remaining kidney at the time of nephrectomy. However, he has shown a serious deterioration in renal function in the succeeding years secondary to amyloid, which affected the remaining kidney. Amyloidosis has been described previously in association with xanthogranulomatous pyelonephritis in four patients, ${ }^{23-25}$ including one child. ${ }^{25}$ Nephrectomy does not seem to halt the progression of the secondary amyloidosis in these patients. For this reason, it is strongly recommended that children who have had surgical intervention for xanthogranulomatous pyelonephritis should be retained on a long term follow up basis.

1 Malek RS, Greene LF, DeWeerd JH, Farrow GM. Xanthogranulomatous pyelonephritis. $\mathrm{Br} \quad \mathcal{F}$ Urol 1972;44:295-308

2 Malek RS, Elder JS. Xanthogranulomatous pyelonephritis: a critical analysis of twenty-six cases and of the literature. $\mathcal{F}$ Urol 1974;119:589-93.

3 Avnet LN, Roberts TW, Goldberg HR. Tumefactive xanthogranulomatous pyelonephritis. AfR Am f Roentgenol 1963;90:90-6.

4 Black WC, Ragsdale EF. Wilms' tumor. AfR Am f Roentgenol 1968;103:53.

5 Gingell JC, Roylance J, Davies ER, Penry JB. Xanthogranulomatous pyelonephritis. Br f Radiol 1973;46:99-101.

6 Graivier L, Vargas M. Xanthogranulomatous pyelonephritis in childhood. Am $\mathcal{F}$ Dis Child 1972;123:156-8.

7 Lackner H, Wolfel D, Banowsky L, Kornfield M. Xanthogranulomatous pyelonephritis. F Pediatr 1969;75:482-4.

8 Bagley FH, Stewart AM, Jones PF. Diffuse xanthogranulomatous pyelonephritis in children: an unrecognised variant. f Urol 1977;18:434-5.

9 Schulman CC, Denis R. Xanthogranulomatous pyelonephritis in childhood. [letter ] $\mathcal{F}$ Urol 1977;117:398.

10 Shapiro SR, Adelman RD, Link D, Tesluk H, Phillips H. Shapiro SR, Adelman RD, Link D, Tesluk H,
Renal mass in an infant. f Urol 1978;120:485-9.

11 Moller JC, Kristensen I. Xanthogranulomatous pyelonephritis. Acta Pathol Microbiol Scand 1980;88:89-96. 
12 Yazaki T, Ishikawa S, Ogawa Y, et al. Xanthogranulomatous pyelonephritis in childhood: case report and review of Engpyelonephritis in childhood: case report and review
lish and Japanese literature. $\mathcal{F}$ Urol 1982;27:80-3.

13 D'Costa GK, Nagle SB, Wagholikar UC, Nathani RR. Xanthogranulomatous pyelonephritis in children and adults - an 8 year follow-up. Indian F Pathol Microbiol 1990; 33:224-9.

14 Nihiri MN, Njah M, Sellami F, Rebai T, Smida ML. Xanthogranulomatous pyelonephritis in children. Report of eight cases. Ann Pediatr (Paris) 1990;37:657-62.

15 Galle JH, Klein-Robbenhaar T, Hayslett JP. Influence of age on the compensatory response in growth and function to unilateral nephrectomy. Yale f Biol Med 1974;47:218-26.

16 Phillips TL, Leong GF. Kidney cell proliferation after unilateral nephrectomy related to age. Cancer Res 1967;27: 286-92.

17 Karp R, Braser JC, Winick M. Compensatory kidney growth after uninephrectomy in adult and infant rats. $A m \mathcal{F}$ Dis Child 1971;121:186-8.

18 Watson AR, Marsden HB, Lendon M, Morris Jones PH. Renal pseudotumours caused by xanthogranulomatous pyelonephritis. Arch Dis Child 1982;57:635-37.
19 Hammedeh MY, Buick RG, Nicholls G, Calder CJ, Corkery JJ. Xanthogranulomatous pyelonephritis in childhood: preoperative diagnosis is possible. Br F Urol 1994;73:83-6.

20 Klugo RC, Anderson JA, Reid R, Powell J, Cerny JG. Xanthogranulomatous pyelonephritis in children. $\mathcal{F}$ Urol 1977; 117:350-2.

21 Mydlo MD, Reda E, Gill B, Kogan S, Levitt S. Xanthogranulomatous pyelonephritis in children. Urology 1987;30:464-6.

22 Kierce F, Carroll R, Guiney EJ Xanthogranulomatous pyelonephritis in childhood. Br F Urol 1985;133:236-9.

23 Lauzurica R, Felip A, Serra A, et al. Xanthogranulomatous pyelonephritis and systemic amyloidosis-a report of 2 new cases and the natural history of this association. 7 Urol 1991;146:1603-6.

24 Garber BB, Cendron M, Cohen R, Whitmore WE. Xanthogranulomatous pyelonephritis and amyloidosis: a rare association. F Urol 1989;142:114-16.

25 Querfield U, Waldherr R, Twittenhoff W, et al. Generalized amyloidosis secondary to xanthogranulomatous pyelonephritis. Eur f Pediatr 1986;145:565-6.

\section{APEC}

Paediatricians and dermatologists in the Aquitaine region of France were informed of the clinical features of asymmetric periflexural exanthem of childhood (APEC) and asked to report cases to paediatric dermatologists in Bordeaux (Didier Coustou and colleagues. Archives of Dermatology 1999;135:799-803). They came up with 67 cases (37 girls) between April 1994 and December 1996.

The condition affected mainly toddlers (mean age 28 months, range 1-5 years). Peak onset was in September, $90 \%$ of cases presenting between February and September. There were no cases in relatives or contacts. There was an erythematous rash consisting of convergent micropapules and starting usually on one side of the trunk near the axilla but later spreading centrifugally. Both sides of the body were eventually involved in $70 \%$ of cases. A prodrome involving the upper respiratory or gastrointestinal tracts was noted in $60 \%$ and fever in $40 \%$. Itching $(65 \%)$ and lymphadenopathy $(70 \%)$ were common. The rash lasted typically for two or three weeks but it persisted for seven weeks or more in eight children. Skin biopsy specimens in nine cases had infiltration with $\mathrm{T}$ lymphocytes predominantly around sweat glands.

APEC, which is said to have been described first in 1962, appears to be a specific and fairly common childhood exanthem. Its cause is unknown but infection seems probable.

ARCHIVIST 